\title{
REFLECTIONS AND PROJECTIONS ON AMERICAN FEMINISM AND CULTURE: AN INTERVIEW WITH GLORIA STEINEM
}

\author{
Melissa Friedling and Susan Biesecker-Mast
}

This interview was conducted in September, 1995, when Gloria Steinem visited Iowa City during her book tour for the second edition of Outrageous Acts and Everyday Rebellions. Republished in 1995, initially published in 1983, and consisting of essays first released as early as 1963, Outrageous Acts provides an occasion for us to think between decades of American feminist political, cultural, and academic endeavor. As academic feminists of the third wave, we took this opportunity to engage Gloria Steinem as a public intellectual whose cultural work calls us to interrogate both contemporary culture's "friendly" incorporations and recent "feminist" hostile repudiations of the legacy that is the second wave. ${ }^{1}$

SBM: In your Playboy bunny expose as re-released in Outrageous Acts you reveal that the well-paid, glamorous, on-her-way-to-stardom bunny was really an underpaid and sexually harassed cocktail waitress, squeezed into a corset. From this article we learned that the Hugh Hefners of this world lie, and that the women who work for them, do so out of necessity. Thus, you helped us to understand that duped bunnies are really exploited waitresses. In Revolution From Within you expanded our understanding further by showing us how education, religion, the fashion industry, etc., seduce women into wanting to think linearly, orworship god-the-father, or sport a miniskirt. Thus, you inspired us to call "sister" not only the bunny who is really a waitress, but also the waitress who really wants to be a bunny. This expanded analysis seems terribly important because it helps us have grace for the masculinist mistakes we all make, and to have empathy for even the most "duped" among us. Yet, If we say that our desires are culturally produced, in order to have empathy for one another, on what grounds can we fight for, or even know, what it is women want?

I think we begin to suspect that our choices may be political when we see that we are following an existing pattern in society. That doesn't per se mean it's not a personal choice, but the alarms begin to go off when we see that we are impelled 
toward or there seems to be no choice other than what is the predominant one, two, or three. When we're faced with more subtle choices, as women are now more likely to be (compared to, say, 25 years ago), I think we have more opportunity to examine what we really as individuals want to do or should do or "what's right for the individual." The interplay between culture and individuality and between community and person is always going to be very complicated and very subtle, because we are both unique human beings and communal creatures.

But I do, as I get older, have more faith in the existence within each of us of a self that is both communal-shared, human, connected-to-all-other-livingthings - and unique. It's as if the millennia of heredity and environment have been combined in each of us in a way that both shares all human characteristics, but also has them in a unique combination that could never have happened before and could never happen again.

So the question becomes, "What are we impelled toward?" Now, this is a hard argument to make in a materialist-rationalist society that in education, even at its best, tends to treat kids like blank slates on which you can write anything and, at its worst, treats them like little animals whose spirits have to be broken. But I think it's true. You know, I think that anyone who's ever met a baby knows that there's a person in that baby already. There's the seed of what can become. If we flout too much what is already in the baby, that baby will grow up thinking there's something wrong with a portion of herself or himself and that feeling that there's something wrong seems to be the source of most future problems. It's the source of addictions, the source of violence, the source of feeling you must be in a hierarchy in order to be better than others or worse than others or dependent.

So while we both respect each other's choices and the pressures under which we make those choices, I think there are unmistakable signs in us of what is more suited to us as a unique person. The signs are joy. The signs are interest. The signs are forgetting everything that's around you because you're so part of what you're doing, whether it's making a bookcase, or solving a computer problem, or talking to another person, whatever it may be. It's a kind of forgetfulness of all that's around you and a feeling of satisfaction that means that you might continue to do it whether you get paid or not. I don't mean to be romantic about it, because that isn't a feeling that happens all the time, but it happens in moments of unity with the task at hand. And if we allow ourselves to be guided by those moments, I think we will continue to make progress and support each other in our search for those moments.

MF: I' $m$ wondering if the work that you have done to expose the pain that lies beneath glamorous images has prompted you to notice the appearance of popular autobiographies (like Roseanne's, for example) that reveal intense suffering in the private lives offemale celebrities. Not only do these celebrities describe the physical, emotional, and economic abuse they secretly endured, they often recount the discovery of something like a feminist self. These confessionals seem to serve an important function as social critique and feminist consciousness-raising. However, when we consider that these best selling books are marketed as "titillating tell-alls," a question emerges. Given your position on pornography, 
which you reiterate in the introduction to Outrageous Acts, and the likelihood that these books sell in proportion to the number of graphic tidbits provideddetailing women's submission to violence and domination-should we reject them as pornographic, or embrace them as feminist affirmations, or something else? ${ }^{2}$

I hadn't thought that there was any real danger of their being treated as pornography because pornography is the depiction of female degradation and slavery (or a man playing the part of a female in that kind of power relationship) as sexual, as titillating, as joyful, as satisfying, as inevitable. And these stories don't say that. They are exposing the pain behind the glamour. In a way they're showing the sham of pornography by showing that there is a real person, in real pain, in situations that might otherwise be considered pornographic. In general, I think it's a plus because these women are telling the truth, or as close to the personal truth as we get when we speak. Because they have a public persona they will be read by women who are swimming in the popular culture, who know these celebrities, and who would not be attracted by obscurity, perhaps, or by words that end in "tion," in an academic way. It's like a public consciousness-raising group, which is very helpful. However, there are dangers to this approach.

One is that the woman is legitimately in a victim status. It's important that we speak about that status and not be scared off by people who talk about victim feminism, but it's also true that we're more acceptable to the dominant culture when we're in that status. It's okay for women to sing the blues, but it's not okay for us to win. So these celebrities may be, to some extent, being accepted for the wrong reasons, in the same way that it's more okay now for us to talk about how many women are raped but it's not okay to talk about how many men are rapists. It's presenting ourselves in the status of someone who has been "done to."

The second problem is that the real solutions are rarely presented. Usually it's an individualized story that is presented as support or partial remedy or whatever, without a group action by women, which is what happens in real life. Such a story may contribute to a real solution by joining the chorus of voices in a public consciousness-raising group. But if the problem is presented with no solution, it can be disempowering.

I think, for instance, of The Accused, a popular film that was presented as a step forward for feminism, which was modeled after the New Bedford rape case. ${ }^{3}$ Now, that was a step forward in the sense that it presented the principle that people who stand around and passively watch a rape are also guilty and because it was patterned on this real rape. However, the movie falsified the remedy in the following way: it gave you the impression that this working class woman who was raped on a pool table in this bar was "rescued" by a woman in the prosecutor's office who came forward and made this creative argument. This isn't what happened. What happened in real life was that, though there is probably a rape like that in every town in America every week, what made this one different was that there was a women's center in New Bedford of rather long standing. There were white women, black women, and Portuguese women in this center together. The women's diversity was very important because the accused 
rapists were Portuguese and they were saying that the accusation was racist. These women, together, marched through the main street of New Bedford every night for maybe a month carrying lighted candles. That captured the attention of the press, and the press in turn forced the prosecutor's office to take her charge seriously. That's not in the movie.

I know that the movie makers knew about this because they sent me the script before it was done. I said, "But you must, you must, put in the real situation here, because otherwise the individual woman is going to wait for the prosecutor's office to rescue her and that's rarely going to happen." They still didn't do it. So the star system in the movies lends itself to this problem as does our whole cultural focus on individuals and individualism. It's counter, by its very nature, to what a movement is about, what a movement demands, and how groups of people move forward.

SBM: Lately it has become a commonplace for commentators, feminist and otherwise, to warn that feminism should not say or in any way imply that women are victims. Doing so is badforfeminism, they say, because it renders women powerless to make the very changes feminism advocates. Therefore, many of these folks conclude, the women's movement should abandon victim feminism and embrace power feminism. ${ }^{4}$ Iffeminists take this advice, that is, if they stop saying or even implying that women are victimized and instead emphasize that women already have power, on what grounds could we then make a case for change? Put more simply, if women aren't victims, but rather are powerful, then what do we need a movement for?

I am very impatient with the phrase "victim feminism" because I think it's just a way of shutting us up. But it is true, as I was saying, that it's easier for a woman to come to the public in a victim stance because its is implicitly a feminine stance. So, the point is balance. We need to be able to say both things. We need to be able to tell when we are victims and we need also to be able to search for the point of power within ourselves and understand that we can express power even though it's not "feminine." As usual, when presented with an either/or dichotomy, it's bullshit.

There are not two sides to every issue. There are one, twelve, one hundred and thirteen. And I really think, in my heart, that this dichotomized view comes basically from trying to divide human nature into masculine and feminine, comes from yin-yang, up-down, subject-object, winner-loser, this kind of notion which is in and of itself false. It kills complexity, it kills subtlety, it kills the opportunity to find other solutions. It's not a choice between power feminism and victim feminism. Neither one actually exists, really. It's about being able to tell the truth, to express one's self as an individual in a supportive community. That means that we have the right to joyfully express our power as long as it doesn't infringe on the freedom of others. And I do think women are trying very hard to redefine power so that it is no longer the power to tell other people what to do, but the power to govern our own lives. Now, some of the reasons we're redefining power are good and some are not so good, because part of it is that we're afraid to ex- 
press power. But in any case, we are, for both positive and negative reasons, trying to redefine power. And we need to be able to express it.

It's true that if you present only the problem you can disempower people. So if you present only a story of victimization, you can make others feel disempowered. But usually what happens, in my experience, is that telling a true story inspires other people who say, "That happened to you? I thought that only happened to me." That relieves the feeling of personal fault, and is the first step out of a victim status. If these stories are silenced, then people are going to go on thinking that this uniquely happened to them and therefore is their fault.

SBM: Just to follow up on what you were saying there about the up and down, yin and yang, subject-object: from what I can tell, as much as you speak of balance and both/ands, you do not, however, seem to be in favor of something like androgyny wherein we achieve a balance between masculinity and femininity within the human being. Is that an accurate understanding?

I don't think we're at a place where we can really approach androgyny yet, because of what is wrongly considered feminine in society. Those human qualities haven't been honored enough. So when we look at a model of androgyny, it's desexed. It's more masculine than feminine. In my heart, I don't believe for a moment that there's such a thing as a masculine or a feminine quality, except culturally. I think we all have all human qualities in a unique way. And if you consider cross-culturally what those qualities are, you become more and more convinced because they change from one culture to the next so deeply.

I know that we're in the middle of a new wave of biological determinism-the gendered brain, and all of that-but even if it were true (which I don't believe it is for a moment) it would still be accurate to say that the individual differences are greater than the group differences, for all purposes other than procreation when it comes to sex differences or for all purposes other than resistance to certain diseases (or whatever) when it comes to race differences. For $98 \%$ of human endeavor the individual difference is greater than the group difference. And that's what matters. My skepticism rises more because the notion of the bell curve (which, incidentally, was really directed against young black women having babies; nobody really looked at that part of it, but the recommendations of social policy in The Bell Curve mostly had to do with women) or the influence of hormones on brain development and all that stuff comes up, as it always does, at times of challenge to the caste systems based on sex and race. ${ }^{5}$ It seems to me another wave of craniology, really.

In addition to its timing, I'm also suspicious because when I see people I know who are (so-called) multiple personality disordered-people who have suffered extreme, long term, sadistic child abuse and survived through developing an ability to dissociate - they often have personalities of the opposite gender as well as of the same gender. A little boy who is sexually abused by a man (little boys are most likely to be abused by a heterosexual man) invents a female personality because otherwise what's happening to him is unacceptable. Or a girl who is being abused invents a male persona in order to be safer or to express her anger. But a lot 
of folks have different gender persona or ego states, as they're called. And when the person changes persona, the brain function that is usually perceived as gendered also changes. Women are supposed to have a better ability to use both hemispheres in an integrated way, for instance. But when a man enters a female persona within himself, the brain pattern changes. Now that we can map the living brain, we can see this. This is the same person, and this happens in 30 seconds or less.

So, I think the human possibilities are so enormous and the individual differences are so interesting and endlessly exciting that people who are still hooked on gross labels of race and sex really are acting politically. To put that much emphasis on these things that are so gross-it is really likely to have politics behind it.

SBM: So, would the advantage for feminism of speaking on behalf of gender difference be primarily in the effort to revalue those cultural behaviors that have so far been devalued?

To revalue them and to raise them up, to make them available to everyone, men and women. That's all very, very crucial.

Maybe you can explain to me because you're in the academic world more than I am why there are people who accuse people, Carol Gilligan for instance, of biological determinism, when my reading of Carol Gilligan tells me that she's not talking at all about biology? She's talking about culture. ${ }^{6}$ And she has performed a great service in saying that there are different patterns and not just one way of arriving at an ethical conclusion. The old hierarchy of ethics is not the only one. I don't quite understand why the resentment is so great.

Here's my theory, though. You can tell me if this right or not. I think that there are a number of women who have risen through the masculinist discipline of academia and for whom, when other women come along saying that the so-called feminine qualities are valuable, are embarrassed by us. They feel like we're eating watermelon. Hey, they just spent all this time becoming rational, non-emotional thinkers, and now we come along and say maybe the emotions are valuable tools of perception after all, or maybe the family model is not such a bad one. It's not the only one, but it's one that we should bring into the mainstream in terms of, as Gilligan says, keeping the group together as a goal rather than submitting every situation to law or to transferable legal principles.

MF: I think that academic feminism is also thinking in terms of other strategies for refunctioning these very images of women and toward really embracing those things that you're calling feminine.

But do you find in academia that there's a kind of resentment of the non-intellectual, intangible arguments?

MF: The charge of essentialism is immediately leveled against you if you bring up woman qualities or motherhood.

Does essentialism, in your experience, mainly mean biology?

MF: Well not for me. I think an essential something is important, say, for a femi- 
nist political movement. We've got to claim there's something essential about us that gives us our radical edge in order to claim that sexism exists, it's bad, and we can do something about it collectively. If there is no essence to an " $u$, " where do you go?

But it's a culturally produced essence, not a biological one. I don't agree with the "motherhood" argument, because there are women who kill their children. There were female guards in Nazi concentration camps. We can't say it's biological, but it is enormously strong, culturally.

SBM: I think academics hesitate to revalue motherhood for fear that doing so produces a reactionary rhetoric that will only serve to put us back where we were.

No, that I agree with. We need to talk about "parenthood." It's interesting to see all these studies showing that men who are single parents acquire the same psychological characteristics as women who are both parents and employed outside the home. In spite of all the conditioning, in just a few years, and once you have this leap of empathy to a child, you start to acquire more patience, flexibility, compassion-whatever is considered feminine.

MF: In the introduction to Outrageous Acts you look back with both anger and encouragement at the last 12 years of feminist history. In that time feminism's appearance, not only as a news item, but more often as an element of mainstream popular discourse, might be considered a benchmark in women's movement history. Recently, for example, the Miss America pageant publicized and conducted its unprecedented call-in poll, which was not only to discover whether or not the television audience wanted to see the contestants compete in bathing suits, but also to determine whether or not this Miss America tradition would even take place. ${ }^{7}$ On the one hand, we could say that the pageant was making a public acknowledgment, and even an endorsement, of feminist demands and tactics. On the other hand, we could say that the survey merely capitalized on feminism's history as a controversial moment while trivializing feminist issues. So the question is this: should we be encouraged or concerned by this kind of mainstream commercial use of feminist histories and strategies? In other words, is this a story of feminist progress or backlash?

I think it was a set-up, per se, because Miss America is a beauty contest. That's what it is. It's like asking, "Is snow wet? Call your 900 number and tell us if snow should still be white or should we make it blue." On the other hand, to be honest, I would have been very heartened if the results had come out the other way. I have to admit that. So, I must have had some investment in this process, emotionally.

In general, I think the problem with this kind of absorption into the popular culture is that it behaves as if the female half of the population was sealed in an airtight compartment with no men. To me, it's like the discussion of working mothers. We can't have this discussion until we talk about working fathers. As long as we're in this little closed capsule of discussion and the question is "Can women do it all? Can women not do it all?" and there is no discussion of the other 
parent or of communal responsibility for children, you can't find an answer. It's not possible. And it just makes women feel like whatever they're doing is wrong whether they're staying home or going out to work. Either thing is wrong. That's the sign of an oppressive system to me. When whatever you do is wrong, you know you're in some kind of oppressive system.

This is similar because nobody posed the question, "Do you think there should be a Mr. America contest? Do you think that it would make sense for men to replicate what is true for women, which is that the Miss America contests, and beauty contests in general, are the single greatest source of scholarship money for women without reference to ability or need?" The whole context would change. You'd begin to see, if beauty contests for men were the single greatest source of scholarship money, that we'd be saying, "That's why the Japanese are winning." So I suspect that most questions can't be answered if they are only asked about one portion of the population, including this tiny little silly question about the bathing suit element of the Miss America contest.

MF: I am concerned about where we see feminism being co-opted into the popular. The Miss America call-in poll was presented as if feminism and Miss America are no longer antagonists, as if there's no problem anymore. In fact the pageant seemed to be saying: "We're going to do a sort of feminist survey and find out what women out there want." Are we to celebrate that the pageant has acknowledged feminism in this way?

It's not to be celebrated. We didn't design this survey. We didn't come up with the idea of the 900 number. Nobody asked us. And I don't think anybody asked the contestants either. What was interesting was that some of the contestants said they thought the bathing suit contests should cease to exist, and none of them won.

Suppose a minstrel show was some great event on television, and the question was asked to the populace, "Should white people appear in blackface? Dial your 900 number, yes or no." Probably they would say "yes": A) because it's sort of a libertarian question-you have a right to do it (just like you have a right to show up in a bathing suit) — and B) because that's what the show is.

But though I agree with you about this instance of the popularization of feminism as being a crock, I don't think we should be afraid of the popularization of feminism. That's what we want. So we should beware of the sixties. You didn't live through this but I remember the 60 s kind of old-fashioned male revolutionary conviction that anything that was popular had to be bad, which I think came largely from white radicals with private incomes. It certainly didn't come from the civil rights movement that wanted to pervade the culture, wanted to win, wanted to succeed. But there was this other idea that failure was good and success was corrupt. And that's a built-in way of assuring our defeat, if we accept that notion.

SBM: One of the lessons the third wave seems to have drawn from the second wave is that exclusion-whether it be of lesbians in the name of political efficacy or of African-American women in the name of an easier sisterhood or of pub- 
lished authors in the name of egalitarianism-was a mistake in the 1970s and would be wrong today. Indeed, one of the distinctive features of third wave feminism seems to be a commitment to avoiding the repetition of that mistake. Yet, as one after another feminist detractor claiming to be a feminist (i.e., Camille Paglia, Katie Roiphe, Christina Hoff Sommers, Rene Denfeld) comes forward to tell a story of how she has been excluded from the movement, I can't help wondering about the wisdom of this very important ethical commitment. So I ask: is the third wave confronted with an important test of its resolve to be inclusive, or is it just being guilt-tripped into welcoming the fox into the rabbit hole?

What third wave folks need to think about, what we all need to think about, is whether we're responding to the real thing or the image of the thing. There was, especially in the early days of NOW, a period of time when [the movement] was white, heterosexual, professional women for the most part, and was exclusive in that way. But that passed pretty quickly, actually, and though I wouldn't for a moment underestimate the problems of the divisions of all kinds between and among women, it's also true that the epithet that the movement is white middle class is not true. It's not true in the public opinion polls. It's not true in the way organizations outline their issues. It's not true in my life experience.

You know, I spent the first ten, fifteen years, I think, wandering around the country speaking in black/white pairs. And I fear that what's happening is that some younger, or third wave, feminists are mistaking the image for the reality. So they're saying, "Well, the reason those folks couldn't succeed in being seen as diverse is because they weren't diverse." And that doesn't prepare them for what's going to happen to them, which is that they are also going to be called white middle class even though they are diverse, too. So you need to look at the other side of it, which is why reporters go into a Republican party meeting and don't report it as white middle class, even though you could go snow blind in there. There's no race or color at all. Why is this uniquely happening to the women's movement? Otherwise, you won't be prepared for that.

There's also a kind of whiff of moral superiority, because I notice it's mostly young white feminists who stand up and say, "Well, it's been a white middle class movement up until now." When they do that they wipe out every womanof-color feminist there has been for 25 years. They end up rendering invisible the women who have, in fact, always been there by saying that. So I think we need to be very careful about knowing what we're responding to.

When it comes, however, to the white middle class self-designated feminists you're talking about—-those authors [Paglia, Roiphe, etc.]-I think feminism is marked, not just by being a self-proclaimed feminist (though I certainly support the right of everybody to call themselves whatever they want), but by your actions. And if your actions are far more negative towards other women-all other women - than they are positive, I think that maybe other people have a right to be skeptical. If you're not walking like you talk or if you're talking totally negative about other women, I think there may be something else going on here.

We have to understand that we are, in this time, now, at a place where it's an advantage to say you're a feminist, at least if you're going to trash other femi- 
nists. So we have Clarence Thomases. Camille Paglia is the Clarence Thomas of feminism. Clarence Thomas is not going to get up and say he's against civil rights, but he is. Those are his actions. And I notice he's now getting picketed by black groups because of those actions. Camille Paglia doesn't say she's antifeminist, because that's not popular, but she is in much of what she says: women wanting to get beaten up, wanting to get raped, it's our fault, AIDS is a punishment for sin-all of these things that she says. We have to exercise some judgment here and look at people's actions.

Incidentally the other thing that's interesting about this group is that their books really don't sell. I mean, they aren't right wing enough for the right wing and they aren't speaking the truth of women's experience enough for their natural constituency. So Katie Roiphe's book, for instance, which I know the best because it was published by my publisher, came into Little, Brown as a manuscript. The male editor gave it to a young female assistant. Said: "Look, this is about young women, you're a young woman. You read it and tell me what you think." So the young female assistant read it and said, "This doesn't reflect my experience. It doesn't reflect the experience of anybody I know. I think this is a destructive book." She turned herself inside out writing her opinion, a thoughtful opinion, of what was wrong with this manuscript. Whereupon the male editor said, "It made you mad? Good. It will sell. I'll publish it." She just felt completely wiped out by this - as if she didn't exist. It was picked up by the media extraordinarily. It appeared in the New York Times several times; [there were] interviews with her mother. It was all over the media and it still didn't sell. So we have to realize that the sowing of dissension serves a purpose. I'm not questioning that it's her experience. I assume she's telling the truth. But it must not have resonated with that many other women's experiences.

SBM: Is it unwise, then, to devote a number of pages in Ms. magazine to Susan Faludi's attempt, for example, to respond fact-for-fact to the likes of Christina Hoff Sommers if what we're talking about are books that really don't resonate with women anyway? ${ }^{8}$

That's always a hard question. It's a tactical question. Are you bringing more attention to a false set of arguments by responding or not? I think we just need to take it on a case by case basis and figure it out. During the Equal Rights Amendment, for instance, that long struggle, we sort of came to a tactical conclusion that only people less well known than Phyllis Schlafly would debate her. In other words, we would try to deal with her falsehoods about the Equal Rights Amendment but not bring her a larger audience.

I think that there was an academic journal that responded to all the myriad falsehoods in Christian Hoff Sommers and that was helpful because what it did was to give you this whole sheaf of papers you could just give to somebody and say, "Here, here's what's wrong." You know, [Sommers] says, "Well, there are more women on campus than men and that's proof of equality." But what she doesn't say is that a lot of those women are older because they couldn't get in before. So again, it's not “either/or" usually. There's usually another more creative alternative. 
I do think that Susan Faludi performed a valuable function by writing that piece just as she did in her book Backlash. By naming what's wrong, by naming the backlash, she made a lot of other women feel less crazy because they've been experiencing this but they didn't have a name for it. And similarly, by showing the inaccuracy of these folks who actually call themselves feminists, she supported the perception of a lot of other people. We got a huge positive response to the piece, and I don't think we got any negative responses.

MF: We've been talking about the domestic front offeminism and clearly the big thing on our minds right now is that you just got back from Beijing.

I didn't go to Beijing. In the end I didn't go. I was all set to go. I had a ticket and everything and then I thought, we should all do what we can uniquely do, and there are lots of women going to Beijing. I had lots of things to do here that no one else would do if I didn't do them. So I was thinking of not going and then I went to Washington to be the sort of $\mathrm{MC}$ for a press conference. There were 20 different women leaders of organizations, all of whom were going to Beijing, and I was doing the introducing and so on. Nonetheless, the press questions mostly came to me and to Bella [Abzug] and I said, "I' $m$ not here as a leader of an organization. I will respond but you should really be asking ..." And that made me realize it would probably be good if I didn't go. Because if I didn't go, the press would ask other people more questions than they would have had I gone. And they would discover there were plenty of other people who could answer these.

MF: If you can get young women to appreciate the importance of global feminism, how then do you also sustain their commitment to American feminism?

I think, speaking from my own observation and experience, that you really most reliably realize feminism out of your own experience. If you realize it only as applicable to dowry murders in India or some other far away atrocity (female genital mutilation, or something that's far away), you are, in any case, in danger of being a liberal—of saying, "Let me help you people." And only if you see that female genital mutilation is actually only different in degree from the Freudian clitoridectomy that was performed on women in this culture, or that it has a considerable amount in common with unnecessary surgery and cosmetic surgery, and so on, only then do you really become useful. Because then you're not being a missionary. You're two people with different degrees of the same problem who come together to try to do something about it. So, as all politics is local, I think feminism is personal, and political. But I mean it's rarely far away.

But Beijing or those kinds of big international meetings are very, very important. And the distance we have come, from the beginning of the conferences about women's issues to now, is enormous. The NGOs (non-governmental organizations) used to be well-meaning lady-like groups that were flattered to be invited in for tea. Now, they're organized into international caucuses that examine every UN document, every phrase, every word, for its impact on women. They suggest alternate wording, picket, go on hunger strikes, influence their national delegations. Women-centered NGOs have provided a model for the way that we 
could and should relate to the UN overall, that environmentalists, that everybody else, should be relating to the UN_not just through governments, but around the heads and over the heads of governments, or pressuring governments with a specific goal of changing international documents.

And of course they're great places just in that women meet each other, and nothing is more important than that. And I'm sorry that I missed that. I know that if I had gone, I wouldn't have been able to imagine not going. But I do think that I was able to do more, in this case, by staying home and making the press quote somebody else.

SBM: A final question. You do such beautiful things with anecdotes. Indeed, so much of your work is about the particular example or specific instance of women's experience that it strikes me as odd how, in just a few places and in the context of comments about wasting time, you make the rather grand statement that "time is all there is." What does that mean?

I just mean it literally. It just means that if we don't live in the present, we can't live. I was chiding myself for my habit of living in the future. I've never had a problem with living in the past. That I don't do. But I do live in the future, as a result of a childhood in which I was always trying to get out. So I was always thinking forward. But to be fully present, one can only do it in this moment.

Notes

${ }^{1}$ Many thanks to Carol Friedling for her careful transcription of this interview.

${ }^{2}$ In her influential essay, "Erotica vs Pornography," originally published in Outrageous Acts in 1977, Steinem calls pornography "anti-woman propaganda" and claims that pornography involves the "imitation of the male-female, conqueror-victim paradigm" (241). While pornography confuses sex with aggression, Steinem suggests that erotica might disentangle the two and "rescue sexual pleasure" (241). She advocates a concerted feminist effort to oppose pornographic imaging and distribution. Similarly in "The Real Linda Lovelace," which also originally appeared in Outrageous Acts, Steinem exposes the violence and sexual abuse that was perpetrated on the star of the X-rated film Deep Throat (1972). In Steinem's new preface, she maintains the urgency of a feminist anti-pornography agenda and responds to what she perceives as a general distortion of anti-pornography feminist interests.

${ }^{3}$ See The Accused, dir. Jonathan Kaplan with Jodie Foster and Kelley McGillis, 1988.

${ }^{4}$ The supposed competing traditions of "victim" and "power" feminism are defined and opposed to one another in Naomi Wolf's Fire With Fire: The New Female Power And How To Use It, paperback edition (New York: Fawcett Columbine, 1994). According to Wolf women have for too long sought power "through an identity of powerlessness" (135). Thanks in large measure to the ideological mistakes of the second wave, Wolf argues, "victim feminism" has taken hold of women's identities and, thereby, "slowed women's progress, impeded their self-knowledge, and been responsible for most of the inconsistent, negative, even chauvinistic spots of regressive thinking that are alienating many women and men" (135). Wolf's corrective is "power feminism"-a feminism grounded in the recognition of women's past achievements, hopeful toward their future accomplishments, and inclusive of "feminist" and "non-feminist" positions alike. For other, similar critiques of the "excesses" of second wave feminism, see Camille Paglia, Sex, Art, and American Culture: Essays (New York: Vintage Books, 1992); Christina Hoff Sommers, Who Stole Feminism? How Women Have Betrayed Women (New York: 
Simon and Schuster, 1994); Katie Roiphe, The Morning After: Sex, Fear, and Feminism (New York: Little, Brown, 1993); Rene Denfeld, The New Victorians: A Young Woman's Challenge to the Old Feminist Order (New York: Warner Books, 1995).

${ }^{5}$ Richard J. Herrnstein and Charles A. Murray, The Bell Curve: Intelligence and Class Structure in American Life (New York: Free Press, 1994).

${ }^{6}$ Carol Gilligan, In a Different Voice (Cambridge: Harvard UP, 1972). Gilligan's influential revisionist work on psychological theories of gender and morality offers an alternative interpretation to traditional moral development theory and particularly the social contract theories of Lawrence Kohlberg. Gilligan claims that women have a different and better moral imperative than men and a distinctively "feminine voice" (71). Gilligan challenges moral theories that privilege justice and rights insofar as they exclude or disadvantage women. Instead, Gilligan offers a model of moral reasoning that privileges women's tendencies to make moral judgments based on responsibility and care. Gilligan is credited with advancing the distinctive feminist framework of "mothering theory." See Judith Grant, Fundamental Feminism (New York: Routledge, 1993) 61. Gilligan's valorizing of an attitude of care in women as complementary to masculine ethics of justice has been repudiated by some feminists on the grounds that such valorization reinscribes gender stereotypes and, thereby, reinstalls legitimations for the continuing oppression of women. For an overview of critiques and suggestions for new appropriations of Gilligan's work, see Rosalyn Diprose, The Bodies of Women: Ethics Embodiment and Sexual Difference (New York: Routledge, 1994).

7“Miss America '96,” NBC, 16 September 1995.

${ }^{8}$ Susan Faludi, “'I'm Not A Feminist But I Play One On TV,"” Ms. March/April 1995: 30-39. 